\title{
Common Hemoglobinopathies for Couples Premarital Individual and its Influence on Hemostasis and Immune State
}

\author{
Fatimah Kadhim Ibrahim AL- Mahdawi', Noor Nayyef Oudah ${ }^{2}$, Mazin Razooqi Mohammed ${ }^{3}$ \\ 1,2Medical Laboratory Technology Department, Bilad Al-Rafidain University College, \\ ${ }^{3}$ Consultant Doctors, Baqubah Teaching Hospital,Diala Health Directorate, Iraq
}

\begin{abstract}
Before marriage, couples are screened through a procedure known as premarital screening for different genetic, infectious or bloodborne diseases that can be passed from them to their offspring. The aim of our research was to assessment the premarital screening of couples for hemoglobinopathies and undiagnosed cases with suggestive findings of thalassemia or its variants. and evaluation hematology parameters among common $\mathrm{Hb}$ hemoglobinopathy. This study contains 228 individuals with hemoglobinopathy, the participants were couples attending primary health centers for regular premarital inquiries in baquba teaching hospitals, Iraq. $\alpha$-thalassemia was enrolled in $3(1.3 \%)$ from all hemoglobinopathy individuals, $\beta$-thalassemia was enrolled in 255 (98.8\%), which include $\beta$-thalassemia minor in 226 individuals $88.6 \%$, while $\beta$ thalassemia intermediate in 5 individuals $2.2 \%$ from all individuals with hemoglobinopathy Figure 1 and 2. Others thalassemia was recorded $3 \mathrm{Hb}-\mathrm{E} 1.1 \%, 1 \mathrm{Hb}-\mathrm{S} 0.39,10 \mathrm{Hb}-\mathrm{D} 3.92,13 \mathrm{Hb}-\mathrm{C} 5.09$. Pre-marital examinations are important to determine hemoglobinopathy and limit transmission to offspring, as well as blood tests are important to identify people with haemoglobinopathy and its influence.
\end{abstract}

Keywords: Hemoglobinopathies, Premarital Individual, hemostasis, immune state.

\section{Introduction}

Before marriage, couples are screened through a procedure known as premarital screening for different genetic, infectious or bloodborne diseases that can be passed from them to their offspring ${ }^{(1)}$. Among the most common autosomal recessive disorders affecting humans, haemoglobinopathies are assessed and are characterized by the existence of qualitative and/or quantitative anomalies affecting the globin chains ${ }^{(2)}$.

The most common qualitative anomalies are haemoglobin $(\mathrm{Hb}) \mathrm{S}$, which causes $\mathrm{Hb}-\mathrm{C}$ or $\mathrm{Hb}-\mathrm{D}$ disease of the sickle cell (SCD) and others, and the most common quantitative anomalies with decreased or absent alpha- or $\beta$-globin chain synthesis lead to alpha- and $\beta$-thalassemias, respectively ${ }^{(3,4)}$. These are the world's

\section{Corresponding Author:}

Mazin Razooqi Mohammed

Consultant Doctors, Baqubah Teaching Hospital,Diala

Health Directorate, Iraq

e-mail:majidmahmood93@yahoo.com most common single gene disorders, particularly in the Eastern Mediterranean Region, including $\operatorname{Iraq}^{(5)}$. Premarital screening for thalassemia and sickle cell anemia was required in 2004 by the Third Royal Decree. According to this decree, couples getting married must receive a certificate specifying their thalassemia and sickle cell anemia status from the approved health centers after being checked. Another essential role of this initiative is the therapy of couples at risk ${ }^{(6)}$.

This study aimed to assess the premarital screening of couples for hemoglobinopathies and undiagnosed cases with suggestive findings of thalassemia or its variants, and evaluation hematology parameters among common $\mathrm{Hb}$ hemoglobinopathy.

\section{Material and Method}

This study contains 228 individuals with hemoglobinopathy, The participants were couples attending primary health centers for regular premarital inquiries in baquba teaching hospitals, Iraq. By using standard laboratory procedures the hemoglobin electrophoresis on cellulose acetate (at $\mathrm{pH}$ 8.6) was 
carried out on all (228) samples. The HbA2 level was calculated by alkaline denaturation using elution from cellulose acetate and $\mathrm{HbF}^{(7)}$.

$\beta$-thalassemia minor was diagnosed by an elevated $\mathrm{HbA} 2$, while $\beta$-thalassemia major was diagnosed by an elevated $\mathrm{Hb}-\mathrm{F}$, and others (Hb-E, Hb-S, Hb-D, Hb$\mathrm{S})$ trait by a positive test confirmed by $\mathrm{Hb}$ band on electrophoresis. $\alpha$-thalassemia trait was diagnosed by an absence of $\mathrm{Hb}$ variants or any increases in $\mathrm{Hb} \mathrm{A} 2$ orHbF${ }^{(8)}$, table 1.

Table 1: Normal haemoglobins in Fetus and adult blood

\begin{tabular}{|l|c|c|}
\hline Hemoglobin & Globin chains & Volume \\
\hline Fetus & $\alpha 2 \gamma 2$ & $85 \%$ \\
\hline $\mathrm{Hb} \mathrm{F}$ & $\alpha 2 \beta 2$ & $5-10 \%$ \\
\hline $\mathrm{Hb} \mathrm{A}$ & $\alpha 2 \beta 2$ & $96-98 \%$ \\
\hline Adult & $\alpha 2 \delta 2$ & $0.5-3.2 \%$ \\
\hline $\mathrm{Hb} \mathrm{A}$ & $\alpha 2 \gamma 2$ & $0.5-0.8 \%$ \\
\hline $\mathrm{Hb} \mathrm{A} 2$ & $\mathrm{Hb} \mathrm{F}$ &
\end{tabular}

Statistical Analysis: Statistical analysis was achieved by using SPSS 20.0 software (SPSS, Inc., Chicago, IL, USA). Continuous variables were expressed as the mean \pm standard error. Dichotomous variables were expressed as percentages. ANOVA was achieved to estimate the differences in continuous variables between the common hemoglobinopathies groups. $\mathrm{P}<$ 0.05 was considered to indicate a statistically significant difference.

\section{Results}

$\alpha$-thalassemia was enrolled in $3(1.3 \%)$ from all hemoglobinopathy individuals, $\beta$-thalassemia was enrolled in 255 (98.8\%), which include $\beta$-thalassemia minor in 226 individuals $88.6 \%$, while $\beta$ thalassemia intermediate in 5 individuals $2.2 \%$ from all individuals with hemoglobinopathy Figure 1 and 2. Others thalassemia was recorded $3 \mathrm{Hb}-\mathrm{E} 1.1 \%, 1 \mathrm{Hb}-\mathrm{S} 0.39,10$ Hb-D 3.92, 13Hb-C 5.09 Figure 3.

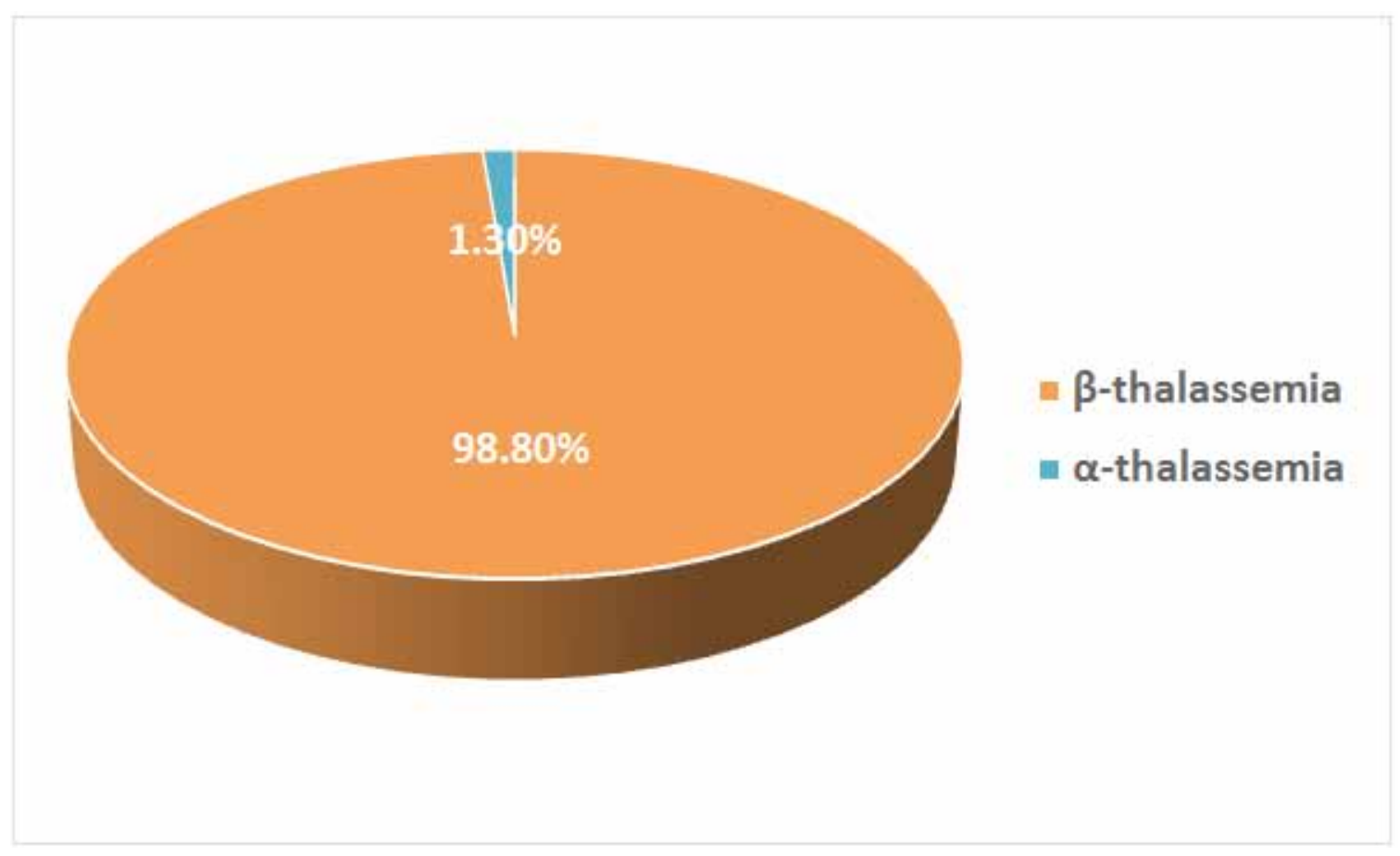

Figure 1: The percentage of $\beta$ - and $\alpha$-thalassemia 
Figure 2: The percentage of $\beta$-thalassemia minor and major

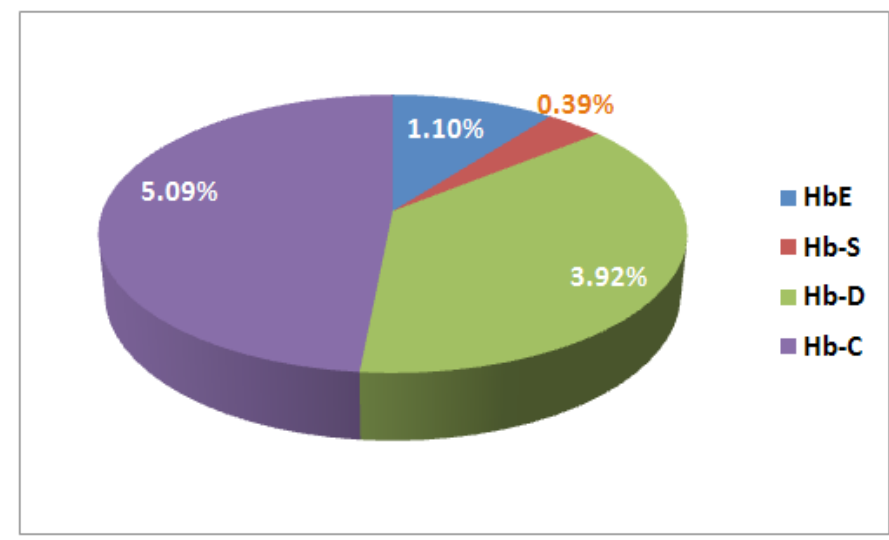

Figure 3: The percentage of others $\beta$-thalassemia

Table 2 illustrated $\mathrm{Hb}$ electrophoresis, the mean $\mathrm{Hb}$ A0, A1c, A2, F level in $\alpha$-thalassemia patients was $(70.5 \%, 9.9 \%, 1.7 \%, 25.3 \%$ respectively). And in in $\beta$-thalassemia minor patients was $(80.32 \%, 5.0 \%, 4.9 \%$, $6.6 \%$ respectively). While in $\beta$-thalassemia intermediate patients was $(48.8 \%, 5.1 \%, 6.8 \%, 30.1 \%$ respectively). Others hemoglobinopathies the mean $\mathrm{Hb} \mathrm{A} 0, \mathrm{~A} 1 \mathrm{c}, \mathrm{A} 2$,
$\mathrm{F}$ level in $\mathrm{Hb} \mathrm{E}$ beta thalassemia patients was $(64.43 \%$, $4.8 \%, 25.6 \%, 0.9 \%$ respectively), Hb Sickle disease patients was $(58.5 \%, 5.4 \%, 3.4 \%,<0.8 \%$ respectively), $\mathrm{Hb} \mathrm{D}$ beta thalassemia patients was $(54.47 \%, 5.05 \%$, $5.05 \%,<0.8 \%$ respectively), and $\mathrm{Hb} \mathrm{C}$ disease patients was $(56.39 \%, 4.93 \%, 3.2 \%,<0.8 \%$ respectively).

Table 2: Mean Hb Electrophoresis Results in Various Hemoglobinopathies

\begin{tabular}{|c|c|c|c|c|}
\hline Hemoglobinopathy & A0 \% & A1c \% & A2 \% & F \% \\
\hline$\alpha$-thalassemia & 70.5 & 9.9 & 1.7 & 25.3 \\
\hline$\beta$-thalassemia minor & 80.32 & 5.0 & 4.9 & 6.6 \\
\hline$\beta$-thalassemia intermediate & 48.8 & 5.1 & 6.8 & 30.1 \\
\hline $\mathrm{Hb} \mathrm{E}$ beta thalassemia & 64.43 & 4.8 & 25.6 & 0.9 \\
\hline Hb Sickle disease & 58.5 & 5.4 & 3.4 & $<0.8$ \\
\hline $\mathrm{Hb} \mathrm{D}$ beta thalassemia & 54.47 & 5.05 & 5.05 & $<0.8$ \\
\hline $\mathrm{Hb} \mathrm{C}$ disease & 56.39 & 4.93 & 3.2 & $<0.8$ \\
\hline
\end{tabular}


Table 3 illustrated hematological parameters in common hemoglobinopathies the white blood cells showed increased significantly in $\beta$-thalassemia intermediate and decrease significantly in $\mathrm{Hb} \mathrm{E}$ beta thalassemia when compared with others groups. As well as the platelets showed decrease significantly in $\beta$-thalassemia intermediate and increased significantly in in $\mathrm{Hb} \mathrm{E}$ beta thalassemia when compared with others groups.

Table 3: Hematological Parameters in Common Hemoglobinopathies

\begin{tabular}{|l|c|c|c|}
\hline Hemoglobinopathy & $\begin{array}{c}\text { WBC } \\
\mathbf{M} \pm \mathbf{S E}\end{array}$ & $\begin{array}{c}\text { RBC } \\
\mathbf{M} \pm \mathbf{S E}\end{array}$ & $\begin{array}{c}\text { PLT } \\
\mathbf{M} \pm \mathbf{S E}\end{array}$ \\
\hline$\alpha$-thalassemia & $8.70 \pm 1.29$ & $5.15 \pm 0.13$ & $154.00 \pm 0.00$ \\
\hline$\beta$-thalassemia minor & $10.27 \pm 0.81$ & $6.15 \pm 0.30$ & $305.55 \pm 40.02$ \\
\hline$\beta$-thalassemia intermediate & $14.33 \pm 0.00$ & $5.15 \pm 0.00$ & $153.00 \pm 0.00$ \\
\hline Hb E beta thalassemia & $5.65 \pm 0.78$ & $5.22 \pm 0.02$ & $374.00 \pm 0.00$ \\
\hline Hb Sickle disease & $7.80 \pm 0.00$ & $4.43 \pm 0.00$ & $357.00 \pm 0.00$ \\
\hline Hb D beta thalassemia & $11.42 \pm 0.98$ & $4.97 \pm 0.21$ & $283.25 \pm 57.24$ \\
\hline Hb C disease & $9.38 \pm 0.68$ & $5.67 \pm 0.14$ & $274.91 \pm 35.99$ \\
\hline
\end{tabular}

\section{Discussion}

The premarital screening program is essential for genetic disorders as it dictates the prevalence and potential transmission of these disorders to the offspring.

The most prevalent abnormal finding observed in our study was $\beta$-thalassemia minor $(88.6 \%)$, while the $\alpha$-thalassemia reached $(1.3 \%)$. Studies performed in Jeddah (West) and Al-Hassa (East) found that 4.69 percent and 3.4 percent of individuals had $\beta$-thalassemia trait ${ }^{(9,10)}$. With an average prevalence of carriers of about 4 percent and an estimated 15,000 registered major/ intermediate thalassemia patients throughout the region, $\beta$-thalassemia is a common inherited hematological disorder in Iraq. The sickle cells were found in $(0.39 \%)$ individuals in the studied population. This result is contradictory to the findings of other studies where the recorded prevalence of sickle cell trait $\beta$ thalassemia is $3.4 \%$ and $3.3 \%{ }^{(11,12)}$. Hemoglobin E $(1.1 \%)$ was found to be a small proportion of the studied population. In Jeddah, the prevalence of hemoglobin E recorded was $0.85 \%$ these percentage is low when compared with our result ${ }^{(13)}$.

In our study the platelets showed decrease significantly in $\beta$-thalassemia intermediate and increased significantly in in $\mathrm{Hb} \mathrm{E}$ beta thalassemia when compared with others groups, platelets are activated by free radical from hemoglobin ${ }^{(14,15)}$, RBC phospholipids, thrombin $^{(16)}$, and microparticles ${ }^{(17)}$. Then, after their activation, platelets bind to proteins $\mathrm{S}$ and $\mathrm{C}^{(11)}$. Release thromboxane A2 (TXA2) ${ }^{(18)}$, and form microparticles of platelets ${ }^{(17)}$. Simultaneously, iron overload is also present in $\beta$-thalassemia.] Vitamin $\mathrm{C}$ is decreased due to this iron overload, which may result in platelet defect ${ }^{(19)}$.

Several immunological defects can be found in patients with thalassemia, among which the impairment of neutrophils and macrophage phagocytic and killing functions. In our study the white blood cells showed increased significantly in $\beta$-thalassemia intermediate and decrease significantly in $\mathrm{Hb} \mathrm{E}$ beta thalassemia when compared with others groups. In $\beta$-thalassemia, The white blood cells defect in thalassemic patients may result from dysregulation of the apoptotic cells death pathway $^{(20)}$.

\section{Conclusion}

Pre-marital examinations are important to determine hemoglobinopathy and limit transmission to offspring, as well as blood tests are important to identify people with haemoglobinopathy and its influence.

Source of Funding: Self fund.

Conflict of Interest: No conflict of interest

Ethic Statement: The researchers already have ethical clearance from all required institution and laboratories. 


\section{References}

1. Hamali HA, Saboor M. Undiagnosed Hemoglobinopathies: A potential threat to the premarital screening program. Pakistan Journal of Medical Sciences. 2019; 35(6):1611-1615. doi: 10.12669/pjms.35.6.976

2. AL-Mahdawi FKI, Elia ZN, Kurji HA. Evaluation Inhibin $\mathrm{B}, \mathrm{FSH}$, and $\mathrm{LH}$ in Male with Thalassemia. Indian Journal of Forensic Medicine and Toxicology. 2020; 14(2):2437-2440.

3. Elia ZN, AL-Mahdawi FKI, Berwary NJA. Estimation of anti-thyroglobulin and anti-thyroid peroxidase among thalassemia major patients. Annal of Tropical Medicne and Public Health. 2019; 22(12): DOI: 10.36295/ASRO.2019.221228

4. Hamamy HA, Al-Allawi NAS. Epidemiological profile of common haemoglobinopathies in Arab countries. Journal of Community Genetics. 2013;4(2):147-67.

5. Al Allawi NA, Al Dousky AA. Frequency of haemoglobinopathies at premarital health screening in Dohuk, Iraq: implications for a regional prevention programme. 2010;

6. Rees, D.C. and Arya, R. The haemoglobinopathies', in Clinical Biochemistry: Metabolic and Clinical Aspects. Elsevier, 2014; pp. 550-559.

7. Lewis SM, Bain BJ, Bates I. 2006, eds. 6. Dacie and Lewis practical haematology, 10th ed. Philadelphia, Churchill Livingstone

8. Hoffbrand V, Steensma DP. Hoffbrand's essential haematology. John Wiley \& Sons, 2019.

9. Al Jaouni SA. Prevalence of thalassemia disorders and hemoglobinopathies in Jeddah, western Saudi Arabia. Journal of Applied Hematology. 2010;1(1):43-46.

10. Al-Sulaiman A. Prevalence of $\beta$-thalassemia trait in premarital screening in Al-Hassa, Saudi Arabia. Ann Saudi Med. 2006;26(1):14-16. doi: 10.5144/0256-4947.2006.14

11. Alsaeed AH. Prevalence of hemoglobinopathy disorders in adult patients sent for diagnosis of
Medico-legal Update, April-June 2021, Vol. 21, No. 2

533

anemia in Saudi Arabia. GeneticTest of Molecular Biomarkers. 2012:16(1); 25-29. doi: 10.1089/ gtmb.2011.0087.

12. Al-Sulaiman A. Prevalence of $\beta$-thalassemia trait in premarital screening in Al-Hassa, Saudi Arabia. Ann Saudi Med. 2006; 26(1):14-16. doi: 10.5144/0256-4947.2006.14

13. Galanello R, Origa R. Beta-thalassemia. Orphanet Journal Rare Diseases. 2010，21; 5:11. doi: 10.1186/1750-1172-5-11

14. Unchern S, Laoharuangpanya N, Phumala N, Sipankapracha P, Pootrakul P, Fucharoen S, et al. The effects of vitamin $\mathrm{E}$ on platelet activity in $\beta$-thalassaemia patients. British Journal Hematology. 2003;123: 738-744.

15. Eldor A, Lellouche F, Goldfarb A, Rachmilewitz EA, Maclouf J. In vivo platelet activation in beta-thalassemia major reflected by increased platelet-thromboxane urinary metabolites. Blood 1991;77:1749-1753.

16. Ruf A, Pick M, Deutsch V, Patscheke H, Goldfarb A, Rachmilewitz EA, et al. In-vivo platelet activation correlates with red cell anionic phospholipid exposure in patients with beta-thalassemia major. British Journal Hematology. 1997;98:51-56.

17. Pattanapanyasat $\mathrm{K}$, Gonwong $\mathrm{S}$, Chaichompoo $\mathrm{P}$, Noulsri E, Lerdwana S, Sukapirom K, et al. Activated platelet-derived microparticles in thalassaemia. British Journal of Hematology2007;136:462-471.

18. Eldor A, Durst R, Hy-Am E, Goldfarb A, Gillis S, Rachmilewitz EA, et al. A chronic hypercoagulable state in patients with beta-thalassemia major is already present in childhood. British Journal ofHaematology. 1999;107:739-746.

19. Eldor A. Hemorrhagic tendency in beta-thalassemia major. Israel Journal of Medical Sciences. 1978;14: 1132-1134.

20. Scheel-Toellner D, Wang K, Craddock R, et al. Reactive oxygen species limit neutrophil life span by activating death receptor signaling. Blood. 2004; 104(8): 2557-2564. 